\title{
Novel KCNA5 loss-of-function mutations responsible for atrial fibrillation
}

\author{
Yiqing Yang ${ }^{1,2,3,4,11}$, Jun $\mathrm{Li}^{1,2,3,11}$, Xiaoping Lin ${ }^{1}$, Yanzong Yang ${ }^{5}$, Kui Hong ${ }^{6}$, Lei Wang ${ }^{1}$, Jinqiu Liu ${ }^{5}$, \\ $\mathrm{Li} \mathrm{Li}^{4}$, Dinghong Yan ${ }^{7}$, Dandan Liang ${ }^{1}$, Junjie Xiao ${ }^{1,2,3}$, Hongmei Jin ${ }^{8}$, Jie Wu ${ }^{9}$, Yangyang Zhang ${ }^{10}$ \\ and Yi-Han Chen ${ }^{1,2,3,4}$
}

\begin{abstract}
Accumulating evidence reveals that genetic variants play pivotal roles in familial atrial fibrillation (AF). However, the molecular defects in most patients with AF remain to be identified. Here, we report on three novel KCNA5 mutations that were identified in 4 of 120 unrelated AF families. Among them, T527M was found in two AF families, and A576V and E610K in two other AF families, respectively. The mutations T527M and A576V were also detected in 2 and 1 of 256 patients with idiopathic AF, respectively. The same mutations were not observed in 200 secondary AF patients and $\mathbf{5 0 0}$ controls. Functional analyses revealed consistent loss-of-function effects of mutant KCNA5 proteins on the ultrarapidly activating delayed rectifier potassium currents. These findings expand the spectrum of mutations in KCNA5 linked to AF and provide new insight into the molecular mechanism involved in AF.
\end{abstract}

Journal of Human Genetics (2009) 54, 277-283; doi:10.1038/jhg.2009.26; published online 3 April 2009

Keywords: atrial fibrillation; electrophysiology; genetics; ion channel

\section{INTRODUCTION}

Atrial fibrillation (AF) is the most common cardiac rhythm disorder in clinical practice. ${ }^{1}$ During the lifetime of men and women aged $\geqslant 40$ years, there is about $25 \%$ risk for the development of $\mathrm{AF}^{2}$ This arrhythmia may result in irregular ventricular response, tachycardiamediated cardiomyopathy, heart failure and thromboembolism. ${ }^{3} \mathrm{AF}$ accounts for nearly one-third of strokes in individuals above 65 years of age, and is also an independent predictor of mortality. ${ }^{4} \mathrm{AF}$ is often associated with structural heart diseases or systemic disorders, such as hypertension, coronary artery disease, heart failure, rheumatic heart disease, hyperthyroidism and cardiomyopathies. ${ }^{5}$ However, in nearly $10-20 \%$ of cases, the underlying etiology for AF cannot be identified by routine examination, and such AF is termed 'idiopathic'. ${ }^{6}$ Emerging evidence has strongly suggested hereditary determinants for $\mathrm{AF}^{7,8}$

Genome-wide scan revealed loci on human chromosomes 10q22, ${ }^{9}$ $6 \mathrm{q} 14-16^{10}$ and $5 \mathrm{p} 15^{11}$ that are linked to familial AF. Specific variations in several genes associated with AF were identified and characterized. These AF-related genes are mainly as follows: KCNQ1, which encodes the $\alpha$-subunit of slowly activating delayed rectifier potassium channel (IKs) $;{ }^{12} H E R G$, which encodes the $\alpha$-subunit of the rapidly activating delayed rectifier potassium channel (IKr); ${ }^{13} S C N 5 A$, which encodes the $\alpha$-subunit of the sodium channel; ${ }^{14,15}$ Ankyrin- $B$, which encodes a member of a family of versatile membrane adapters, which is required for coordinated assembly of the $\mathrm{Na} / \mathrm{Ca}$ exchanger, $\mathrm{Na} / \mathrm{K}$ ATPase and inositol trisphosphate receptor at transverse tubule/sarcoplasmic reticulum sites in cardiomyocytes; ${ }^{16}$ KCNJ2, which encodes the $\alpha$-subunit of inward rectifier potassium channel (IK1); ${ }^{17} \mathrm{KCNA5}$, which encodes the $\alpha$-subunit of the ultrarapidly activating delayed rectifier potassium channel (Kv1.5); ${ }^{18}$ Connexin 40, which is expressed selectively in atrial myocytes and mediates the coordinated electrical activation of the atria; ${ }^{19} \mathrm{KCNE} 1$, which encodes the $\beta$-subunit of $\mathrm{IKs} ;{ }^{20} \mathrm{KCNE} 2$ encoding $\beta$-subunit of $\mathrm{IKr} ;{ }^{21}$ and $K C N E 3,{ }^{22} K_{C N E 4}{ }^{23}$ and $K C N E 5,{ }^{24}$ which encode the $\beta$-subunits of potassium channels interacting with KCNQ1, HERG and others. In addition, inheritable defects also confer substantial disease susceptibility on patients with secondary AF. ${ }^{25}$

Nevertheless, AF is a genetically heterogeneous disorder, and genetic defects in a significant proportion of AF patients remain to be identified. ${ }^{26}$ In this study, we describe the identification and characterization of novel KCNA5 mutations as genetic determinants for AF.

\footnotetext{
${ }^{1}$ Department of Cardiology, Tongji Hospital, Tongji University School of Medicine, Shanghai, China; ${ }^{2}$ Key Laboratory of Molecular Genetics of Arrhythmias, Ministry of Education, Shanghai, China; ${ }^{3}$ Heart Rhythm Research Center, Shanghai, China; ${ }^{4}$ Institute of Medical Genetics, Tongji University, Shanghai, China; ${ }^{5}$ Department of Cardiology, First Affiliated Hospital of Dalian Medical University, Dalian, China; ${ }^{6}$ Department of Cardiology, Second Affiliated Hospital of Nanchang University, Nanchang, China; ${ }^{7}$ Department of Cardiology, Second Affiliated Hospital of Zhejiang University, Hangzhou, China; ${ }^{8}$ Department of Cardiology, Affiliated Hospital of Nantong University, Nantong, China; ${ }^{9}$ Department of Cardiology, People's Hospital of Haimen, Haimen, China and ${ }^{10}$ Department of Cardiology, First Affiliated Hospital of Nanjing Medical University, Nanjing, China ${ }^{11}$ These authors contributed equally to this work.

Correspondence: Professor Y-H Chen, Key Laboratory of Molecular Genetics of Arrhythmias, Ministry of Education, China, and Department of Cardiology, Tongji Hospital, Tongji University School of Medicine, 389 Xin Cun Road, Shanghai 200065, China.

E-mail: yihanchen@hotmail.com

Received 29 January 2009; revised 20 February 2009; accepted 3 March 2009; published online 3 April 2009
} 


\section{MATERIALS AND METHODS}

Study subjects

A total of 120 unrelated kindreds with familial AF were identified among the Chinese population. Peripheral venous blood specimens were prepared and clinical data, including medical records, electrocardiogram (ECG) and echocardiography reports, were collected. In addition, 256 unrelated sporadic patients with idiopathic AF were also collected. The controls were 200 unrelated patients with secondary AF and 500 ethnically matched healthy subjects. All study subjects were of Chinese Han descent. The study subjects were clinically classified using a consistently applied set of definitions. ${ }^{11,26}$ Briefly, 'lone AF' was defined as $\mathrm{AF}$ in individuals $<60$ years of age without hypertension or overt structural heart disease by clinical examination, ECG and echocardiography. 'Familial AF' was the lone AF in family members with $\geqslant 2$ first-degree relatives with documented lone AF. Relatives with $\mathrm{AF}$ occurring at any age in the setting of structural heart disease (hypertensive, ischemic, myocardial or valvular) were classified as 'undetermined' for having an inherited form of AF. The 'undetermined' classification was also used if documentation of AF on an ECG tracing was lacking in relatives with symptoms consistent with $\mathrm{AF}$ (palpitations, dyspnea and light-headedness), or if a screening ECG and echocardiogram were not carried out, regardless of the symptoms. Relatives were classified as 'unaffected' if they were $\geqslant 18$ years of age, asymptomatic and had a normal ECG. We have described 'secondary AF' as AF secondary to structural heart diseases or systemic disorders, such as heart failure and hyperthyroidism. Genomic DNA from all participants was extracted from blood lymphocytes with the Wizard Genomic DNA Purification Kit (Promega, Madison, WI, USA). The study was carried out according to the terms required by the Research Ethics Committee of Tongji University School of Medicine. Written informed consent was obtained from all participants.

\section{Genetic investigations}

We initially screened 12 established AF susceptibility genes (KCNQ1, HERG, SCN5A, Ankyrin-B, KCNJ2, KCNE1, KCNE2, KCNE3, KCNE4, KCNE5, KCNA5 and Connexin 40) in 120 probands and identified only three mutations in the KCNA5 gene in 4 of 120 probands. Subsequently, we targeted the KCNA5 gene in the members of the four families carrying identified KCNA5 mutations-256 patients with idiopathic AF, 200 patients with secondary AF and 500 controls. The primers used to amplify the complete coding regions and exon/intron boundaries of these candidate genes were designed with the online Primer 3 software. PCR was carried out using Hot-Star Taq DNA Polymerase (Qiagen, Hilden, Germany). Amplified products were purified with the QIAquick gel
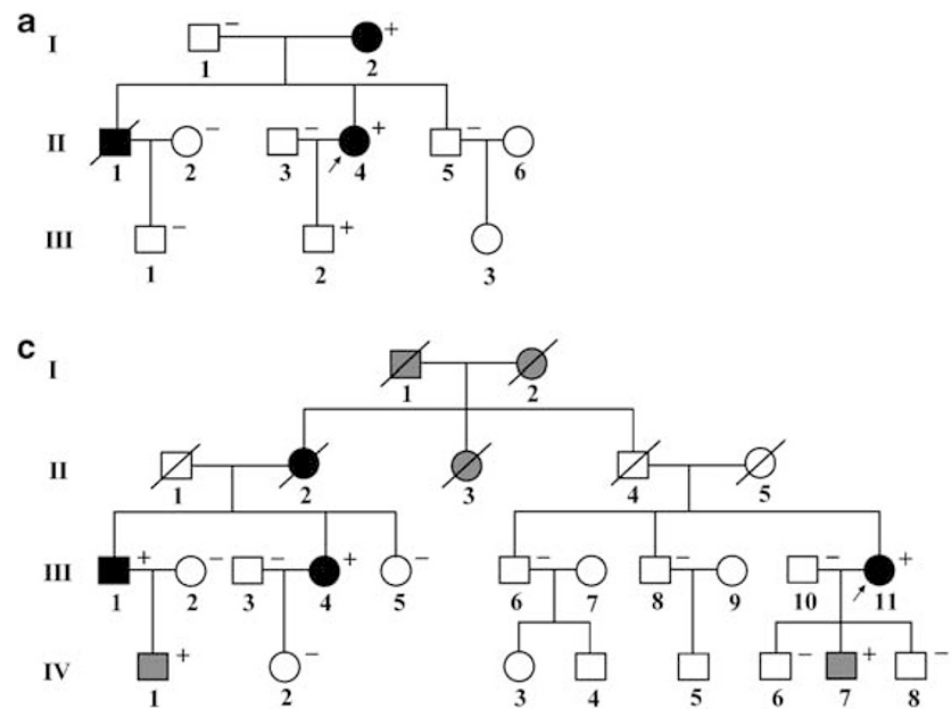

Figure 1 Pedigree structures of four families with AF. Family members are identified by generations and numbers; squares indicate male family members; circles, female members; symbols with a slash, the deceased members; closed symbols, affected members; open symbols, unaffected members; stippled symbols, members with phenotype undetermined; arrows, probands; ' + ', carriers of the respective heterozygous mutation (T527M in families a and $\mathbf{b}, \mathrm{A576V}$ in family c, E610K in family d); and '-', non-carriers. AF, atrial fibrillation.

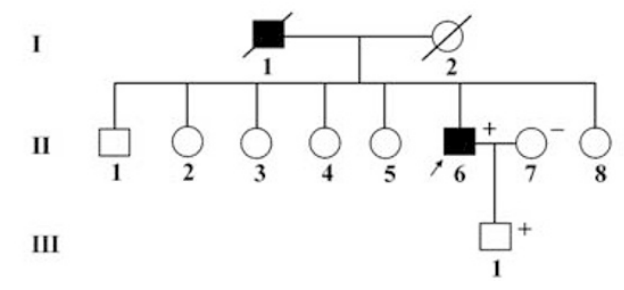

extraction kit (Qiagen). Both strands of each PCR product were sequenced with a DYEnamic ET dye terminator kit (Amersham Biosciences, Little Chalfont, (Amersham Biosciences, Piscataway, NJ, USA).

\section{Sequence comparison}

The multiple Kv1.5 protein sequences from various species were aligned using

\section{Site-directed mutagenesis}

The full-length wild-type cDNA of human KCNA5 was obtained by PCR and inserted into plasmid pGEM-4Z (Promega). Every mutation was introduced into a wild-type KCNA5 clone with a QuickChange II XL Site-Directed Mutagenesis Kit (Stratagene, San Diego, CA, USA). Clones were sequenced appropriate wild-type and mutant KCNA5 cDNAs were transferred into vector pXOOM with enhanced green fluorescent protein (pXOOM-EGFP, a kind gift from Thomas Jespersen, Department of Medical Physiology, The Panum University of Copenhagen, Denmark). The resulting KCNA5pXOOM constructs were corroborated by sequencing before subsequent experiments.

\section{Cell transfection and electrophysiology}

COS-7 cells were transiently transfected with $2 \mu \mathrm{g}$ of wild-type, or $2 \mu \mathrm{g}$ of mutant, or both $1 \mu \mathrm{g}$ of wild-type and $1 \mu \mathrm{g}$ of mutant KCNA5-pXOOM DNAs using Lipofectamine (Invitrogen, Carlsbad, CA, USA). Using the whole-cell patchclamp technique in the voltage-clamp mode, expressed Kv1.5 channels in transfected COS-7 cells were explored after transfection for $48 \mathrm{~h}$. Voltage-step protocols are detailed in figure legends. Patch electrodes, with 5-7 M $\Omega$ resistance, were filled with the solution (in $\mathrm{mm}$ ) of $120 \mathrm{KCl}, 1 \mathrm{MgCl}_{2}, 5 \mathrm{EGTA}$ and 10 HEPES supplemented with $5 \mathrm{~mm}$ of ATP, pH 7.3. Cells were superfused with the glucose, $\mathrm{pH}$ 7.3. Current density was obtained by normalizing whole-cell currents on the basis of individual cell capacitance. Experiments were carried out at room

\section{Statistics}

Data are given as mean \pm s.e.m. Differences between the two groups were compared using $\chi^{2}$ - or Student's $t$-test for continuous variables. All tests were twotailed, with a $P$-value $<0.05$ defined as being statistically significant.

d Buckinghamshire, UK) using MegaBACE 500 DNA Sequencing system to confirm the desired mutation and exclude any other sequence variants. The solution (in mM) of $136.5 \mathrm{NaCl}, 5.4 \mathrm{KCl}, 1 \mathrm{MgCl}_{2}, 1.8 \mathrm{CaCl}_{2}, 5.5 \mathrm{HEPES}$ and 10 temperature $\left(22^{\circ} \mathrm{C}\right)$.

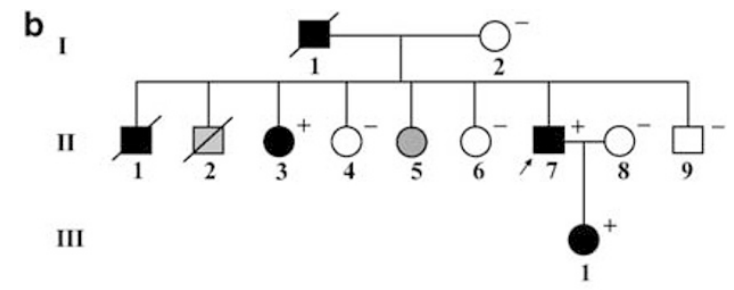



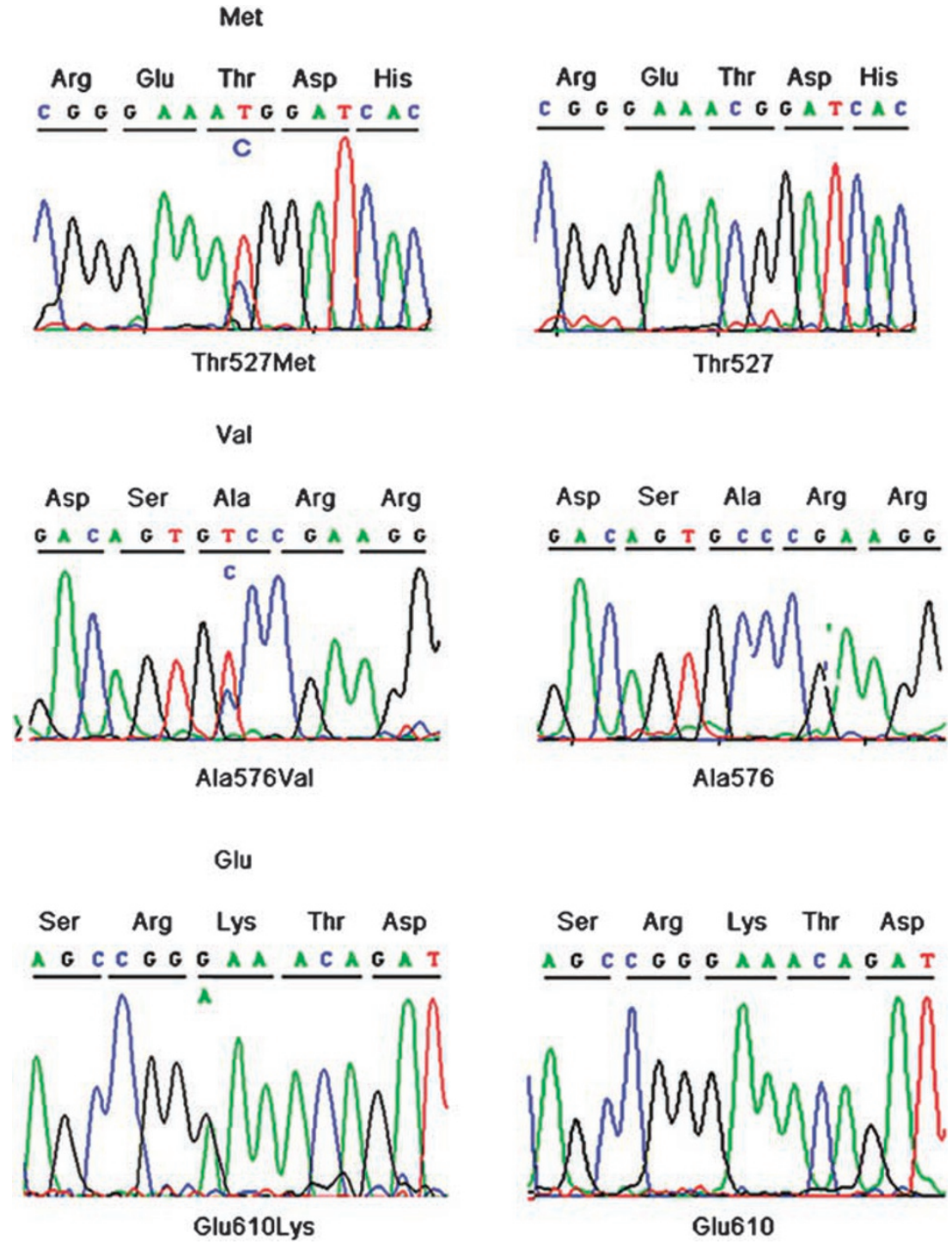

Figure 2 Substitutions detected in KCNA5 in kindreds and patients with idiopathic AF. The figure shows the mutations Thr527Met, Ala576Val and Glu610Lys, respectively (left-hand side). At the right-hand side are their respective wild-type counterparts.

\section{RESULTS}

KCNA5 mutations in AF kindreds and patients with idiopathic AF We identified three novel heterozygous missense mutations in KCNA5 from 4 of the 120 unrelated kindreds with AF. The pedigree structures of the four kindreds are illustrated in Figure 1. The total population prevalence of KCNA5 mutations based on probands was approximately $3.3 \%$. A $1580 \mathrm{C} \rightarrow \mathrm{T}$ mutation, predicting the substitution of methionine (Met, M) for threonine (Thr, T) at codon 527 (Thr527 $\rightarrow$ Met) was identified in 2 (Figures $1 \mathrm{a}$ and b) of 120 families. A 1727 $\mathrm{C} \rightarrow \mathrm{T}$ mutation, corresponding to the conversion of alanine (Ala, A) into valine (Val, V) at amino-acid residue 576 (Ala576 $\rightarrow$ Val), was found in a third family (Figure 1c). A $1828 \mathrm{G} \rightarrow$ A mutation, resulting in the transition of glutamic acid (Glu, E) into lysine (Lys, K) at 610 (Glu610 $\rightarrow$ Lys), was observed in a fourth family (Figure 1d). The detected substitutions in KCNA5 are shown in Figure 2. These mutations cosegregated with $\mathrm{AF}$ in these families, with the exception of III-2 in family A, IV-1 and IV-7 in family C, and III-1 in family D, pointing to the fact that the long-term follow-up of asymptomatic subjects carrying the allele encoding Met527, Val576 or Lys610 will be needed to confirm its clinical significance. In addition, the heterozygous variants Met527 and Val576 were also identified in 2 and 1 of 256 unrelated sporadic patients with idiopathic $\mathrm{AF}$, respectively. The phenotypic characteristics and results of genetic screening of the pedigree members and sporadic patients with idiopathic AF are listed in Table 1. However, the same mutations were not detected in 200 patients with secondary AF and 500 ethnically matched controls. In the other 11 investigated genes, no more mutations were identified in the 120 probands, except those that were reported earlier. ${ }^{12,17,21}$

Multiple alignment of the Kv1.5 protein sequences across species A cross-species alignment of Kv1.5 protein sequences showed that the altered amino acids, except for Ala576, are completely conserved evolutionarily (Figure 3). 
Electrophysiological analysis of KCNA5 mutants

Compared with the equivalent expression of wild-type KCNA5, the COS-7 cells transfected with each of the three mutants showed significantly $(P<0.05)$ smaller ultrarapidly activating delayed rectifier potassium current $\left(I_{\text {Kur }}\right)$. The current density at $+40 \mathrm{mV}$ was $102.3 \pm$ $12.7 \mathrm{pA}^{-1} \mathrm{pF}$ for wild-type KCNA5 $(n=20), 44.27 \pm 6.37 \mathrm{pA}^{-1} \mathrm{pF}$ for E610K $(n=12), \quad 73.55 \pm 1.21 \mathrm{pA}^{-1} \mathrm{pF}$ for T527M $(n=9)$ and $49.72 \pm 4.34 \mathrm{pA}^{-1} \mathrm{pF}$ for A576V $(n=8)$. When each of the three mutants was coexpressed with wild-type KCNA5, the current density produced by the respective heterozygous channel decreased significantly at all positive voltage levels, leading to a roughly $50 \%$ reduction in the net outward current compared with that generated by the expression of wild-type KCNA5 alone (Figure 4). These data indicate that the mutant proteins coassemble into functional channels with wild-type subunits, exerting consistent loss-of-function effects on $I_{\text {Kur }}$ in the heterozygous state.

\section{DISCUSSION}

The cardiac repolarization process is regulated by several outward currents, of which the ultrarapid delayed rectifier potassium current $\left(I_{\text {Kur }}\right)$ is thought to play a major role in the repolarization of human atrial myocytes. ${ }^{27} I_{\text {Kur }}$ is carried by functional channel Kv1.5 assembled

Table 1 Phenotypic characteristics and results of genetic screening of the pedigree members and sporadic patients with idiopathic AF

\begin{tabular}{|c|c|c|c|c|c|c|c|c|c|c|}
\hline \multicolumn{4}{|c|}{ Subject information } & \multirow{2}{*}{$\begin{array}{l}\text { Symptom } \\
\text { Recurrent } \\
\text { palpitation }\end{array}$} & \multicolumn{3}{|c|}{ Electrocardiogram } & \multicolumn{2}{|c|}{ Echocardiogram } & \multirow[t]{2}{*}{ Genotype } \\
\hline Identity & Gender & Age (years) & $\begin{array}{c}\text { Age at AF } \\
\text { diagnosis (years) }\end{array}$ & & $\begin{array}{c}\text { Premature atrial } \\
\text { complexes }\end{array}$ & $\begin{array}{c}A F \\
\text { (classification) }\end{array}$ & $\begin{array}{c}\text { Other ECG } \\
\text { abnormalities }\end{array}$ & $\begin{array}{l}\text { Left atrial size } \\
(\mathrm{mm})\end{array}$ & LVEF (\%) & \\
\hline Family $A$ & & & & & & & & & & T527M \\
\hline I-2 & $\mathrm{F}$ & 72 & 45 & + & + & Permanent & - & 42 & 58 & $+/-$ \\
\hline$\|-1$ & $M$ & $51^{a}$ & 39 & + & - & Paroxysmal & - & NA & NA & NA \\
\hline II-4 & $\mathrm{F}$ & 46 & 42 & + & + & Paroxysmal & $\begin{array}{c}\text { Sinus } \\
\text { bradycardia }\end{array}$ & 36 & 70 & $+1-$ \\
\hline III-2 & $M$ & 16 & NA & + & - & NA & - & 26 & 66 & $+/-$ \\
\hline Family $B$ & & & & & & & & & & T527M \\
\hline |-1 & $M$ & $65^{a}$ & 44 & + & + & Permanent & - & NA & NA & NA \\
\hline$\|-1$ & $M$ & $52^{a}$ & 35 & + & + & Permanent & - & NA & NA & NA \\
\hline $11-3$ & $\mathrm{~F}$ & 66 & 49 & + & + & Paroxysmal & - & 35 & 64 & $+/-$ \\
\hline $11-7$ & $M$ & 53 & 32 & + & + & Permanent & - & 33 & 65 & $+1-$ \\
\hline III-1 & $\mathrm{F}$ & 23 & 23 & + & + & Paroxysmal & - & NA & NA & $+/-$ \\
\hline Family C & & & & & & & & & & A576V \\
\hline II-2 & $\mathrm{F}$ & $68^{a}$ & 45 & + & NA & Permanent & - & NA & NA & NA \\
\hline III-1 & M & 66 & 41 & + & + & Paroxysmal & $\begin{array}{c}\text { Sinus } \\
\text { bradycardia }\end{array}$ & NA & NA & $+/-$ \\
\hline III-4 & $\mathrm{F}$ & 64 & 39 & + & + & Persistent & - & 36 & 68 & $+1-$ \\
\hline III-11 & $\mathrm{F}$ & 57 & 50 & + & + & Permanent & - & 42 & 65 & $+/-$ \\
\hline IV-1 & $M$ & 40 & NA & - & - & NA & - & NA & NA & $+1-$ \\
\hline IV-7 & M & 31 & NA & + & + & NA & - & NA & NA & $+/-$ \\
\hline Family D & & & & & & & & & & E610K \\
\hline I-1 & M & $68^{a}$ & 47 & + & + & Permanent & - & NA & NA & NA \\
\hline $11-6$ & $M$ & 57 & 38 & + & + & Paroxysmal & - & 41 & 56 & $+/-$ \\
\hline III-1 & M & 35 & NA & - & - & NA & - & NA & NA & $+1-$ \\
\hline \multicolumn{11}{|l|}{ Sporadic } \\
\hline Case 1 & $M$ & 64 & 41 & + & + & Paroxysmal & $\begin{array}{l}\text { Sinus } \\
\text { bradycardia }\end{array}$ & 35 & 60 & $\mathrm{~T} 527 \mathrm{M}$ \\
\hline Case 2 & M & 45 & 40 & + & + & Paroxysmal & - & 33 & 72 & T527M \\
\hline Case 3 & $\mathrm{~F}$ & 58 & 52 & + & + & Permanent & - & NA & NA & A576V \\
\hline
\end{tabular}

Abbreviations: AF, atrial fibrillation; F, female; LVEF, left-ventricular ejection fraction; M, male; NA, not available or not applicable.

age at death; +, present; -, absent.

Figure 4 Electrophysiological analysis of mutant KCNA5 proteins. Loss-of-function effects of KCNA5 mutations E610K, T527M and A576V are shown. Representative current traces were recorded from COS-7 cells transfected with wild-type and mutant KCNA5, respectively, and from COS-7 cells cotransfected with wild-type and a different mutant, KCNA5. Current density is plotted versus voltage for the indicated transfections. Cells were held at $-40 \mathrm{mV}$ before depolarization to various potentials ranging from -40 to $+40 \mathrm{mV}$ in $10-\mathrm{mV}$ increments for $200 \mathrm{~ms}$, and thereafter held at $-30 \mathrm{mV}$ for $60 \mathrm{~ms}$. Typical current traces were acquired from COS-7 cells with similar capacitance on rows. 


\begin{tabular}{|c|c|c|c|c|}
\hline & Thr527 & 7 Met & & \\
\hline & 518 & & & 563 \\
\hline Human & NFWYFYHRET & DHEEPAVLKE EQG-TOSQGP & GLDRGVQRKV & ---SGSRGSF \\
\hline Chimpanzee & NFWYFYHRET & DHEEPAVLKE EOG-TQSQGP & GLDRGVQRKV & ---SGSRGSF \\
\hline Monkey & NFWYFYHRET & DHEEPAVLKE EQG-PQSQGP & GLDRGVORKV & OESSGSRGSF \\
\hline Mouse & NFWYFYHRET & DHEEQAALKE EQG-IQRRES & GLDTGGQRKV & ---SCSKASF \\
\hline Rat & NFWYFYHRET & DHEEOAALKE EOG-NORRES & GLDTGGORKV & ---SCSKASF \\
\hline Rabbit & NFWYFYHRET & DHEEQAALKE EPG-\$QSRGT & SLDAGGQRKA & ---SWSKASL \\
\hline Cattle & NFWYFYHRET & DHEEPAAVKE EOG-\$OSOGT & GSAGGGORKA & ---SWSKGSL \\
\hline Pig & NFWYFYHRET & DHEEOAALKE EOG-SOSOGT & GLASGGQRKA & ---SUSKGSL \\
\hline Dog & NFNYFYHRET & DHEEQAALKE EOG-\$0SQGT & GLDSGGPRKT & ---SUSKGSL \\
\hline Fow1 & NFNYFYHRET & DHEEQAMLKE EHSSAQSSIT & GVD--GKRRS & -----SKNSL \\
\hline & & Ala576Val & & Glub10lys \\
\hline & 64 & & & 613 \\
\hline Human & CKAGGTLE & DSARRGSCPL EKCNVKAKSN & VDLRRSLYAL & CLDTSRETDL \\
\hline Chimpanzee & CKAGGTLENA & DSARRGSCPL EKCNVKAKSN & VDLRRSLYAL & CLDTSRETDL \\
\hline Monkey & CKAGGTLENA & DSARRSSCPL EKCNVKAKSN & VDLRRSLYAL & CLDTSRETDL \\
\hline Mouse & CKTGGPLEST & DSIRRGSCPL EKCHLKAKSN & VDLRRSLYAL & CLDTSRETDL \\
\hline Rat & CKTGGSLESS & DSIRRGSCPL EKCHLKAKSN & VDLRRSLYAL & CLDTSRETDL \\
\hline Rabbit & CKAGGSLETA & DSVRRGSCLL EKYNLKAKSN & VDLRRSLYAL & CLDTSRETDL \\
\hline Cattle & CKVAGSLENT & DGSRRGSCSL EKCNLKAKSN & VDLRRSLYAL & CLDTSRETDL \\
\hline Pig & CKAVGALDNA & DGSRRGSCPL EKCNLKAKSN & VDLRRSLYAL & CLDSSRETDL \\
\hline Dog & CKAGVSLENA & DGARRGSCPL EKCNLKAKSN & VDLRRSLYAL & CLDTSRETDL \\
\hline Fow 1 & & EGFKSAS-PL EKTNIKAKSN & VDLRKSLYAL & CLDSSRETDL \\
\hline
\end{tabular}

Figure 3 Multiple alignment of the Kv1.5 protein sequences across species. The amino acids of Thr527 and Glu610 are highly conservative evolutionarily across species.
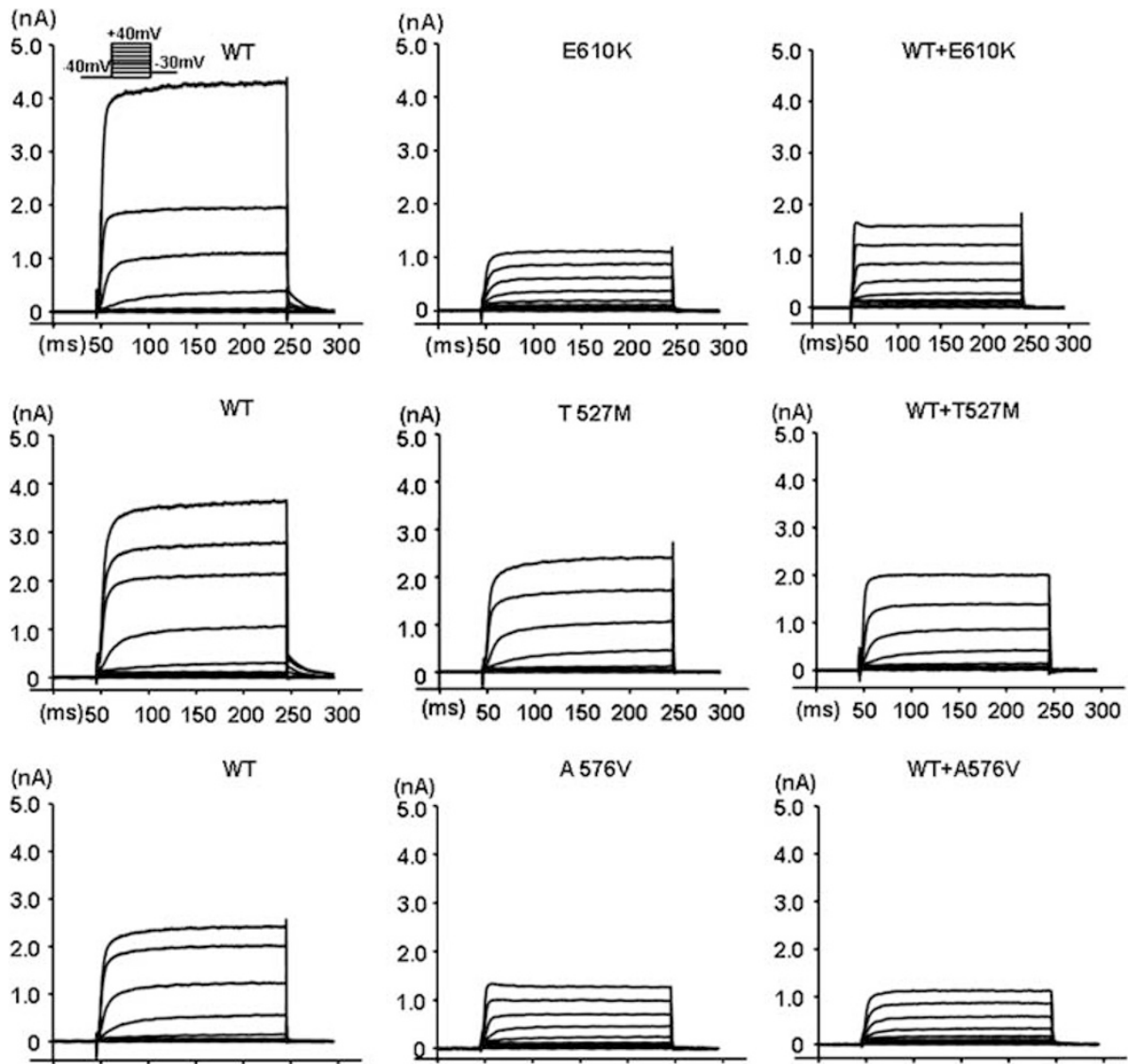

(ms) 50100150200250300
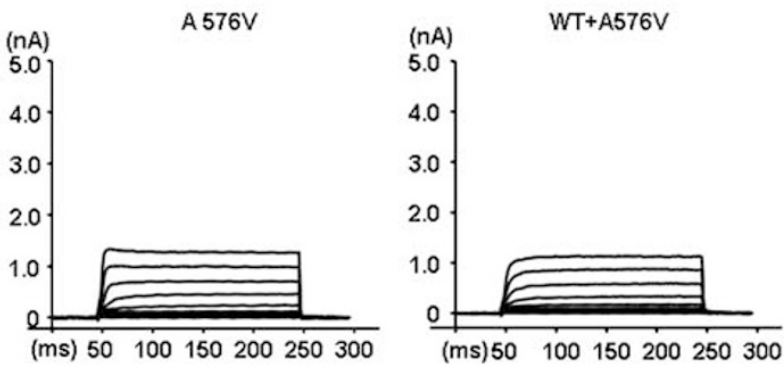
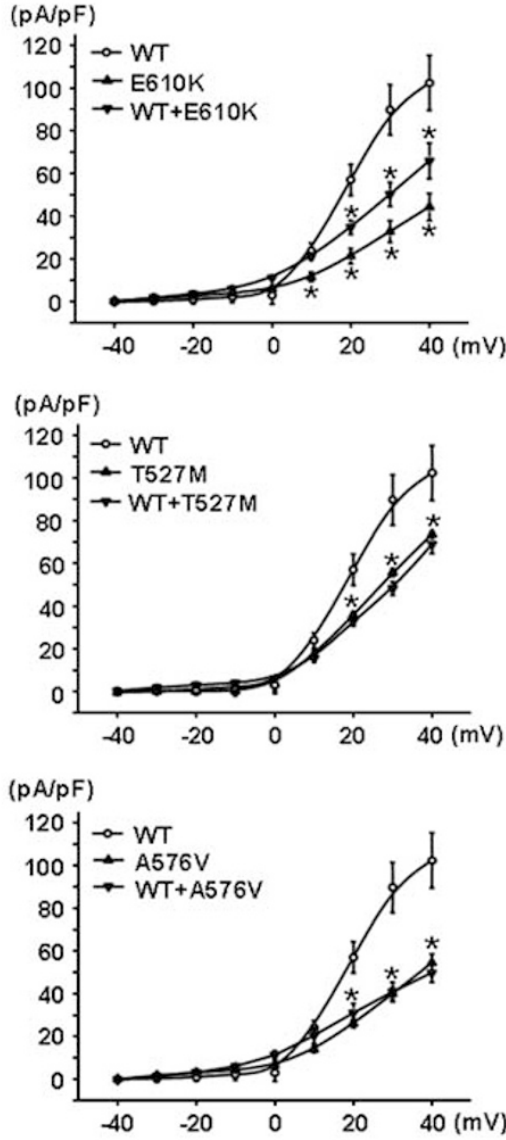
by KCNA5-encoded pore-forming $\alpha$-subunits. The Kv1.5 channel activates and deactivates rapidly, whereas it inactivates only slowly and incompletely. In this study, we report three earlier unrecognized missense mutations, that is, T527M, A576V and E610K, in KCNA5 from 4 of 120 unrelated AF kindreds with a prevalence of approximately $3.3 \%$. Electrophysiological research into the expressed mutant proteins shows consistent loss-of-function effects on $I_{\text {Kur }}$.

The loss-of-function effects of the KCNA5 mutations identified in patients with AF suggest an alternative AF mechanism, which is likely to be due to the prolonged effective refractory period and enhanced propensity for early afterdepolarization, which is exacerbated with sympathetic stimulation. Given the presence of a mutant protein, increased nerve tone as a common precipitant renders affected patients susceptible to AF, presumably by amplifying the already abnormal myocardial electrophysiology.

Association of defective Kv1.5 with susceptibility to AF was highlighted both in vitro and in vivo. ${ }^{18}$ In human atrial myocytes, Kv1.5 loss-of-function mimicked by Kv1.5 blockade with 4-aminopyridine was accompanied by significant prolongation of action potential duration and associated with a predisposition to early afterdepolarization and paroxysmal oscillations in membrane potential that interrupted normal repolarization. Under the condition of adrenergic agonist administration, human atrial myocytes with Kv1.5 channel blocked were concomitant with remarkably increased triggered activity. Besides, the vulnerability to adrenergic stress was also observed in the KCNA5 Glu375X mutation-carrying patient, in whom isoproterenol infusion elicited irregular atrial discharges evolving into overt AF. These findings attest the pathogenic link between compromised Kv1.5 function and susceptibility to AF.

Functionally deficient KCNA5 as a genetic determinant for AF is exciting, especially in optimizing AF therapy. It is well known that existing medication with class I or III antiarrhythmic agents, such as dofetilide and sotalol, ${ }^{28,29}$ could bring about negative feedback impact on the ventricular repolarization, which is generally considered as a critical risk factor for fatal arrhythmias. These life-threatening adverse effects, attributable to the unselective blockade of the potassium currents in both atrial and ventricular cardiomyocytes, ${ }^{30}$ hindered the appropriate application of these antiarrhythmic drugs to patients in clinical practice. Given these limitations, new agents targeting the atrium-selective current may well be an appealing alternative for AF therapy. ${ }^{31}$ Specifically functioning in the atria, $I_{\text {kur, }}$ is a crucial determinant for phase I repolarization during action potentials. ${ }^{32,33}$ The strong evidence that KCNA5 expresses much more extensively in human atria than in ventricles, and that $I_{\text {Kur }}$ has not been recorded in the human ventricle, ${ }^{32,34}$ implicates Kv1.5 as a potential selective target for the medical management of AF. ${ }^{35}$ Importantly, it should be noted that traditional therapeutics for AF are based on inhibition of $I_{\text {Kur }}{ }^{31}$ and would not be applicable in patients with loss of function of Kv1.5. Therefore, it is required to genotype KCNA5 in patients before treatment with Kv1.5-targeted agents for AF.

In conclusion, we identified novel KCNA5 mutations as genetic determinants for AF. Playing a role in AF pathogenesis, but not in ventricular function, KCNA5 genetic defects signify important implications for genetic diagnosis, genetic counseling and atrium-selective strategy for AF therapy.

\section{ACKNOWLEDGEMENTS}

We are indebted to the participants for their dedication to the study. This study was supported by the Natural Science Fund of China for Distinguished Young Scholars (30425016), the Natural Science Fund of China (30330290, 30528011 and 30470961), the '973' (2007CB512100) and '863' Programmes
(2007AA02Z438) of China, the Programme Fund for Outstanding Medical Academic Leader of Shanghai, China, the Programme Fund for Shanghai Subject Chief Scientist, China, the Yangze Scholars Programme Fund by the Ministry of Education, China, and the Programme Fund for Innovative Research Team by the Ministry of Education, China (all to Yi-Han Chen), and by the Natural Science Fund of China (30570768) to Yiqing Yang.

1 Go, A. S., Hylek, E. M., Phillips, K. A., Chang, Y., Henault, L. E., Selby, J. V. et al. Prevalence of diagnosed atrial fibrillation in adults: national implications for rhythm management and stroke prevention: the AnTicoagulation and Risk Factors in Atrial Fibrillation (ATRIA) Study. JAMA 285, 2370-2375 (2001).

2 Lloyd-Jones, D. M., Wang, T. J., Leip, E. P., Larson, M. G., Levy, D., Vasan, R. S. et al. Lifetime risk for development of atrial fibrillation: the Framingham Heart Study. Circulation 110, 1042-1046 (2004).

3 Chugh, S. S., Blackshear, J. L., Shen, W. K., Hammill, S. C. \& Gersh, B. J. Epidemiology and natural history of atrial fibrillation: clinical implications. J. Am. Coll. Cardiol. 37, 371-378 (2001)

4 Benjamin, E. J., Wolf, P. A., D’Agostino, R. B., Silbershatz, H., Kannel, W. B. \& Levy, D. Impact of atrial fibrillation on the risk of death: the Framingham Heart Study. Circulation 98, 946-952 (1998)

5 Nattel, S. New ideas about atrial fibrillation 50 years on. Nature 415, 219-226 (2002).

6 Brand, F. N., Abbott, R. D., Kannel, W. B. \& Wolf, P. A. Characteristics and prognosis of lone atrial fibrillation. 30-year follow-up in the Framingham Study. JAMA 254, 3449-3453 (1985).

7 Fox, C. S., Parise, H., D’Agostino, R. B. Sr, Lloyd-Jones, D. M., Vasan, R. S., Wang, T. J. et al. Parental atrial fibrillation as a risk factor for atrial fibrillation in offspring. JAMA 291, 2851-2855 (2004).

8 Tsai, C. T., Lai, L. P., Hwang, J. J., Lin, J. L. \& Chiang, F. T. Molecular genetics of atrial fibrillation. J. Am. Coll. Cardiol. 52, 241-250 (2008).

9 Brugada, R., Tapscott, T., Czernuszewicz, G. Z., Marian, A. J., Iglesias, A., Mont, L. et al. Identification of a genetic locus for familial atrial fibrillation. N. Engl. J. Med. 336, 905-911 (1997).

10 Ellinor, P. T., Shin, J. T., Moore, R. K., Yoerger, D. M. \& MacRae, C. A. Locus for atrial fibrillation maps to chromosome 6q14-16. Circulation 107, 2880-2883 (2003).

11 Darbar, D., Hardy, A., Haines, J. \& Roden, D. M. Prolonged signal-averaged P-wave duration as an intermediate phenotype for familial atrial fibrillation. J. Am. Coll. Cardiol. 51, 1083-1089 (2008).

12 Chen, Y. H., Xu, S. J., Bendahhou, S., Wang, X. L., Wang, Y., Xu, W. Y. et al. KCNQ1 gain-of-function mutation in familial atrial fibrillation. Science 299, 251-254 (2003).

13 Hong, K., Bjerregaard, P., Gussak, I. \& Brugada, R. Short QT syndrome and atrial fibrillation caused by mutation in $\mathrm{KCNH} 2$. J. Cardiovasc. Electrophysiol. 4, 394-396 (2005).

14 Darbar, D., Kannankeril, P. J., Donahue, B. S., Kucera, G., Stubblefield, T., Haines, J. L. et al. Cardiac sodium channel (SCN5A) variants associated with atrial fibrillation. Circulation 117, 1927-1935 (2008).

15 Makiyama, T., Akao, M., Shizuta, S., Doi, T., Nishiyama, K., Oka, Y. et al. A novel SCN5A gain-of-function mutation M1875T associated with familial atrial fibrillation. J. Am. Coll. Cardiol. 52, 1326-1334 (2008)

16 Mohler, P. J., Schott, J. J., Gramolini, A. O., Dilly, K. W., Guatimosim, S., duBell, W. H. et al. Ankyrin-B mutation causes type 4 long-QT cardiac arrhythmia and sudden cardiac death. Nature 421, 634-639 (2003).

17 Xia, M., Jin, Q., Bendahhou, S., He, Y., Larroque, M. M., Chen, Y. et al. A Kir2.1 gainof-function mutation underlies familial atrial fibrillation. Biochem. Biophys. Res. Commun. 332, 1012-1019 (2005).

18 Olson, T. M., Alekseev, A. E., Liu, X. K., Park, S., Zingman, L. V., Bienengraeber, M. et al. Kv1.5 channelopathy due to KCNA5 loss-of-function mutation causes human atrial fibrillation. Hum. Mol. Genet. 15, 2185-2191 (2006).

19 Gollob, M. H., Jones, D. L., Krahn, A. D., Danis, L., Gong, X. Q., Shao, Q. et al. Somatic mutations in the connexin 40 gene (GJA5) in atrial fibrillation. N. Engl. J. Med. 354, 2677-2688 (2006).

20 Lai, L. P., Su, M. J., Yeh, H. M., Lin, J. L., Chiang, F. T., Hwang, J. J. et al. Association of the human minK gene $38 \mathrm{G}$ allele with atrial fibrillation: evidence of possible genetic control on the pathogenesis of atrial fibrillation. Am. Heart J. 144, 485-490 (2002).

21 Yang, Y., Xia, M., Jin, Q., Bendahhou, S., Shi, J., Chen, Y. et al. Identification of a KCNE2 gain-of-function mutation in patients with familial atrial fibrillation. Am. J. Hum. Genet. 75, 899-905 (2004).

22 Lundby, A., Ravn, L. S., Svendsen, J. H., Hauns, S., Olesen, S. P. \& Schmitt, N. KCNE3 mutation V17M identified in a patient with lone atrial fibrillation. Cell Physiol. Biochem. 21, 47-54 (2008).

23 Zeng, Z., Tan, C., Teng, S., Chen, J., Su, S., Zhou, X. et al. The single nucleotide polymorphisms of $\mathrm{I}(\mathrm{Ks})$ potassium channel genes and their association with atrial fibrillation in a Chinese population. Cardiology 108, 97-103 (2007).

24 Ravn, L. S., Aizawa, Y., Pollevick, G. D., Hofman-Bang, J., Cordeiro, J. M., Dixen, U. et al. Gain of function in IKs secondary to a mutation in KCNE5 associated with atrial fibrillation. Heart Rhythm 5, 427-435 (2008). 
25 Gudbjartsson, D. F., Arnar, D. O., Helgadottir, A., Gretarsdottir, S., Holm, H., Sigurdsson, A. et al. Variants conferring risk of atrial fibrillation on chromosome $4 q 25$. Nature 448, 353-357 (2007)

26 Darbar, D., Herron, K. J., Ballew, J. D., Jahangir, A., Gersh, B. J., Shen, W. K. et al. Familial atrial fibrillation is a genetically heterogeneous disorder. J. Am. Coll. Cardiol. 41, 2185-2192 (2003).

27 Feng, J. L., Wible, B., Li, G. R., Wang, Z. G., Nattel, S. Antisense oligodeoxynucleotides directed against Kv1.5 mRNA specifically inhibit ultrarapid delayed rectifier $\mathrm{K}^{+}$current in cultured adult human atrial myocytes. Circ. Res. 80, 572-579 (1997).

28 Naccarelli, G. V., Wolbrette, D. L., Khan, M., Bhatta, L., Hynes, J., Samii, S. et al. Old and new antiarrhythmic drugs for converting and maintaining sinus rhythm in atrial fibrillation: comparative efficacy and results of trials. Am. J. Cardiol. 91, 15D-26D (2003).

29 Lombardi, F., Borggrefe, M., Ruzyllo, W., Lüderitz, B. \& A-COMET-II Investigators Azimilide vs. placebo and sotalol for persistent atrial fibrillation: the A-COMET-II (Azimilide-CardiOversion MaintEnance Trial-II) trial. Eur. Heart J. 27, 2224-2231 (2006).
30 Elming, H., Brendorp, B., Pehrson, S., Pedersen, O. D., Kober, L. \& Torp-Petersen, C. A benefit-risk assessment of class III antiarrhythmic agents. Expert Opin. Drug. Saf. 3, 559-577 (2004)

31 Yang, Q., Wang, X., Du, L., Li, M. \& You, Q. Strategies for atrial fibrillation therapy: focusing on IKur potassium channel. Expert Opin. Ther. Pat. 17, 1443-1456 (2007).

32 Wang, Z., Fermini, B. \& Nattel, S. Sustained depolarization-induced outward current in human atrial myocytes. Evidence for a novel delayed rectifier K+ current similar to Kv1. 5 cloned channel currents. Circ. Res. 73, 1061-1076 (1993).

33 Van Wagoner, D. R., Pond, A. L., McCarthy, P. M., Trimmer, J. S. \& Nerbonne, J. M. Outward $\mathrm{K}+$ current densities and Kv1.5 expression are reduced in chronic human atrial fibrillation. Circ. Res. 80, 772-781 (1997).

$34 \mathrm{Li}$, G. R., Feng, J., Wang, Z., Fermini, B. \& Nattel, S. Adrenergic modulation of ultrarapid delayed rectifier $\mathrm{K}+$ current in human atrial myocytes. Circ. Res. 78, 903-915 (1996).

35 Page, R. L. \& Roden, D. M. Drug therapy for atrial fibrillation: where do we go from here? Nat. Rev. Drug. Discov. 4, 899-910 (2005). 